\title{
Structural and Electrical Properties of Niobium Doped $\mathbf{Y}_{0.6} \mathrm{Gd}_{0.4} \mathrm{Ba}_{2-x} \mathrm{Nb}_{x} \mathrm{Cu}_{3} \mathrm{O}_{7-y}$ Superconductors
}

\author{
Mucahit Yilmaz $^{1 *}$, Oguz Dogan ${ }^{1}$ \\ ${ }^{1}$ A. Keleşoğlu Education Faculty Department of Physics, Selçuk University, Meram-Konya, Turkey \\ Email: "mucahit@selcuk.edu.tr
}

Received August $9^{\text {th }}, 2010$; revised January $8^{\text {th }}, 2011$; accepted May $30^{\text {th }}, 2011$

\begin{abstract}
Polycrystalline samples of $Y_{0.6} G d_{0.4} \mathrm{Ba}_{2-x} \mathrm{Nb}_{x} \mathrm{Cu}_{3} \mathrm{O}_{7-y}$ (YGBNCO) with different $\mathrm{Nb}$ contents $(x=0.05,0.10,0.15,0.20$, and 0.25 ) were prepared using the usual solid state reaction technique. The structure for all samples was characterized by XRD and SEM. The electrical properties were measured by the FPP method in the temperature range from 70 to 130 $K$. The lattice constant of $b$ remains almost unchanged and $a$ and $c$ increases with the increase of $N b$ content with $x \leq$ 0.10 . The zero resistance transition temperature and $J_{c}$ decrease with increasing Nb content. But superconductivity did not suppress. As the Nb content in the samples increases, it gives a diffused phase indicating a niobium perovskite phase and it is a small amount of unidentified phase.
\end{abstract}

Keywords: $Y_{0.6} \mathrm{Gd}_{0.4} \mathrm{Ba}_{2} \mathrm{Cu}_{3} \mathrm{O}_{7-\mathrm{Y}}$ Cuprates, Gd and $\mathrm{Nb}$ Co-Doping, Structural and Superconducting Properties

\section{Introduction}

YBCO is one of the most widely studied compound among the cuprate superconductors, owing to simplicity of synthesis procedure by solid-state reaction, the easy availability of the starting powders, and the non-toxity of the material compared to the other high- $T_{\mathrm{c}}$ superconductors such as $\mathrm{Tl}$ and $\mathrm{Hg}$ based oxides [1-5].

One of the most fascinating challenges of the material science is to develop $\mathrm{YBa}_{2} \mathrm{Cu}_{3} \mathrm{O}_{7-x}(\mathrm{YBCO})$ and RE$\mathrm{Ba}_{2} \mathrm{Cu}_{3} \mathrm{O}_{7-x}$ (REBCO: $\mathrm{RE}=\mathrm{Er}, \mathrm{Nd}, \mathrm{Gd}, \mathrm{Sm}$ ) superconductors for practical applications [6]. Several attempts have been made to study the effects of substituting $\mathrm{Nb}$ for YBCO [7-13]. In a study by Suresha et al. [14], a resistivity for $\mathrm{YBa}_{2} \mathrm{Cu}_{3-x} \mathrm{Nb}_{x} \mathrm{O}_{7-y}$ sample with $x=0.3$, 0.45 and 0.6 indicated that $T_{c}$ was in the range $85-90.3$ $\mathrm{K}$. They showed a possible change in crystal structure and composition with changing of $x$. Kuwabara and $\mathrm{Ku}-$ saka [13] concluded that $\mathrm{Cu}$ and $\mathrm{Nb}$ did not co-exist in the same compound containing $\mathrm{Y}$ and $\mathrm{Ba}$. Another study by Abdullah and Tan [7] mentioned that the added $\mathrm{Nb}$ formed perovskite $\mathrm{YBa}_{2} \mathrm{NbO}_{6}$ instead of a compound containing $\mathrm{Cu}$. On the other hand, in a study by Eguchi et al. [15] it was shown that $\mathrm{Nb}$ substitute to $\mathrm{Cu}$ in the sample with nominal composition $\mathrm{x}=0.01$. Some researches $[9,16]$ reported the existence of two phases in $\mathrm{Y}-\mathrm{Ba}-\mathrm{Cu}-$ $\mathrm{Nb}-\mathrm{O}$ compound. One is the cubic $\mathrm{Nb}$ perovskite $\mathrm{YBa}_{2}-$ $\mathrm{NbO}_{6}$, and the other is $\mathrm{YBa}_{2} \mathrm{Cu}_{3} \mathrm{O}_{y}$ phase. Some previous works indicated that at a small amount of $\mathrm{Nb}$ content of transition temperature, $\mathrm{T}_{\mathrm{c}}$, of the $\mathrm{Y}-\mathrm{Ba}-\mathrm{Cu}-\mathrm{Nb}-\mathrm{O}$ compound was nearly constant $[9,14,17]$ or slowly higher $[10,18]$.

The effect of Gd substitution in YBCO polycrystalline stabilizes an orthorhombic phase while the lattice parameters are found to increase due to a larger size of the Gd atoms than Y atoms. There is no effect in the transition temperature regardless of the concentration of $\mathrm{Gd}$ atoms introduced in YBCO [18], but $\mathrm{T}_{\mathrm{c}}$ in $\mathrm{Gd} 123$ and Nd123 decreases rapidly with only little oxygen deficiency from fully oxygenated state, while in Y123 highest $\mathrm{T}_{\mathrm{c}}$ is retained even with certain oxygen deficiency (up to $\delta \approx 0.2$ ). This may be one of the reasons why the Gd123 material is not yet considered for various applications as widely as Y123 [19]. The results of X-ray distribution maps of $x=0.4$ composite indicate that the RE123 matrix is homogeneous and $\mathrm{Y}$ and Gd elements in the $\mathrm{Y}_{1-x} \mathrm{Gd}_{x} \mathrm{Ba}_{2} \mathrm{Cu}_{3} \mathrm{O}_{7-\delta}$ a perfect solid solution [20]. For the $\mathrm{Gd}$ diffused-doped samples, magnetization and resistivity measurements show that the critical transition temperature, $\mathrm{T}_{c}$, increased from 88 to $91 \mathrm{~K}$ and the critical current density, Jc, which was calculated from M-H loops taken at $77 \mathrm{~K}$, increased from 55 to $122 \mathrm{~A} \cdot \mathrm{cm}^{-2}$ in comparison with those of undoped Y123. Such enhancement, which is considered to represent a characteristic strength of inter-grain coupling, is more clearly rec- 
ognized when critical current densities are compared [21].

We aimed that $\mathrm{Nb}$ doped to the compound which oxygen concentration is high and it is only a little affected from absence of oxygen. Because when the $\mathrm{Nb}$ substitutes for $\mathrm{Cu}$ in cuprates, $\mathrm{Cu}-\mathrm{O}$ chains and $\mathrm{CuO}_{2}$ planes are distorted, oxygen concentration reduces, thus superconductivity does not disappear. Therefore, we mixed $60 \% \mathrm{Y}_{2} \mathrm{O}_{3}$ and $40 \% \mathrm{Gd}_{2} \mathrm{O}_{3}$. Then we doped $\mathrm{Nb}$ to the $\left(\mathrm{Y}_{0.6} \mathrm{Gd}_{0.4}\right)$ BCO compound. In Section 2, we gave some details about the sample preparation and experiments. Results of the dependences of the superconductivity properties and structural parameters upon the content of $\mathrm{Nb}$ in $\mathrm{Y}_{0.6} \mathrm{Gd}_{0.4} \mathrm{Ba}_{2-x} \mathrm{Nb}_{x} \mathrm{Cu}_{3} \mathrm{O}_{y}$ compound are summarized and discussed in Section 3. Some conclusions have been drawn in Section 4.

\section{Experimental}

The samples were prepared using the standard solid-state reaction technique. The detailed procedures for sample preparation were as follows: pure cation oxides of $\mathrm{Y}_{2} \mathrm{O}_{3}$ (99.995\%), $\mathrm{Gd}_{2} \mathrm{O}_{3}$ (99.99\%), $\mathrm{Nb}(99.8 \%), \mathrm{BaCO}_{3}(99 \%)$, and $\mathrm{CuO}(99 \%)$ were weighted and mixed according to the chemical formula of $\mathrm{YBa}_{2} \mathrm{Cu}_{3} \mathrm{O}_{7-y}(\mathrm{YBCO})$ and $\mathrm{Y}_{0.6} \mathrm{Gd}_{0.4} \mathrm{Ba}_{2-x} \mathrm{Nb}_{x} \mathrm{Cu}_{3} \mathrm{O}_{7-y}$ (YGBNCO) with $x=0.05,0.10$, $0.15,0.20$ and 0.25 , individually. Each of these mixtures was ground ten minutes for several times. They were put into a furnace (Nabartherm-N11/R) and calcined at $925^{\circ} \mathrm{C}$ in air at $48 \mathrm{~h}$. This process was repeated two times. The calcined powders were pulverized and reground then pelletized into disk-shaped pellets. In the sintering process, the pellets were then heated up to $925^{\circ} \mathrm{C}$ in the tube furnace (Carbolite 201) with $10^{\circ} \mathrm{C} / \mathrm{min}$ and kept at this temperature for $24 \mathrm{~h}$ in air. Afterwards the temperature was decreased down to about $550^{\circ} \mathrm{C}$ with $4^{\circ} \mathrm{C} / \mathrm{min}$ and kept at this level for $12 \mathrm{~h}$ in flowing oxygen $(\approx 2.1 / \mathrm{min})$. Finally the products were cooled down to room temperature.

The structural characterization was performed by $\mathrm{X}$-ray diffraction (XRD) and scanning electron microscopy (SEM) which is equipped with an energy dispersive spectrum (EDS). A JEOL JSM-6390LV scanning electron microscope and an EDS were used. EDS analysis was carried out to displayed region with SEM for 1300 count/min. XRD experiments were carried out on Rigaku Multiflex powder diffractometer. At the XRD measurements, $\mathrm{CuK} \alpha$ beam were used at $10^{\circ}<2 \theta<60^{\circ}, 5^{\circ} / \mathrm{min}$ scan speed and $0.02^{\circ}$ sampling space. a, b, c, unit cell dimensions and, $\mathrm{V}$, unit cell volumes were calculated from XRD data using Lapod Program which uses Cohen's method of least square. Electrical properties were measured by a standard four point probe method with silver and indium soldering contacts. The resistivity de- pendence of temperature in the range of $70-130 \mathrm{~K}$ was measured under 10 - 6 Torr pressure with CTI-Cyro-genics Cyrodyne Refrigerator System. Critical current density of samples were measured $77 \mathrm{~K}$ and under $0 \mathrm{~T}$ external magnetic field. Jc value of samples was calculated for $2 \mu \mathrm{V} / \mathrm{cm}$ from I-V curves.

\section{Results and Discussion}

All samples were examined by powder XRD. Figure 1(a) and Figure 1(b) show the measured XRD patterns for samples (a) $\mathrm{YBa} 2 \mathrm{Cu} 3 \mathrm{O} 7$ (Y123), and (b) $\mathrm{Y}_{0.6} \mathrm{Gd}_{0.4} \mathrm{Ba}_{2-x^{-}}$ $\mathrm{Nb}_{x} \mathrm{Cu}_{3} \mathrm{O}_{y}$ (YGBNCO) with $x=0.05,0.10,0.15,0,20$ and 0.25 respectively. The peaks of the undoped sample (YBCO) and Gd doped sample (YGBCO) were well matched to the orthorhombic Y123 structure. As can be seen there is a slight difference in the patterns for the sample with $x=0.00$ compared to the $\mathrm{Nb}$ doped samples. The XRD patterns show that the peaks marked with arrow exist in the spectrum of the samples in Figure 1(b). The peaks were observed at about 29.8 degrees and about 53.1 degrees and the intensity of these peaks increased gradually with the increasing of $\mathrm{Nb}$ content. These peaks were identified as due to niobium perovskite. With increasing $\mathrm{Nb}$ content samples gave a diffused phase indicating a niobium perovskite phase [22] and a small amount of unidentified phase. The results showed that the intensity of peaks owing to the YBCO decreased, while those for $\mathrm{YBa}_{2} \mathrm{NbO}_{6}$ increased with $\mathrm{Nb}$ content. The results of XRD analysis indicate that niobium does not go into the lattice of YBCO, but forms a secondary phase which uniformly distributes in the YBCO compound with improved microstructure. Also, there are some reports that $\mathrm{YBa}_{2} \mathrm{Cu}_{3-\mathrm{x}} \mathrm{Nb}_{\mathrm{x}} \mathrm{O}_{\mathrm{y}}$ could be owing to the compound of this composition was not stable, leading to the formation of three components ( $\mathrm{YBCO}, \mathrm{YBa}_{2} \mathrm{NbO}_{6}$, and $\mathrm{CuO}$ ), and $\mathrm{Cu}$ and $\mathrm{Nb}$ never coexist in the same compound containing $\mathrm{Y}$ and $\mathrm{Ba}$ [7].

Figure 2(a) and 2(b) illustrate typical back-scattered electron SEM micrographs of the samples with $\mathrm{x}=0.10$ and 0.20 . The SEM studies proved that the samples with $x \leq 0.10$ are homogeneous. The SEM micrographs show the homogeneous stone-like grains with typical size of several microns (Figure 2(a) and 2(b)). The SEM micrographs show that the stone-like grains marked with A and the sponge-like grains marked with B co-exist in the surface of the samples (Figure 2(b)). X-ray structural analysis of the samples showed that the sponge-like grains are distributed statistically inhomogeneous. We believe that the $\mathrm{B}$ grains are composed of $\mathrm{Nb}$ impurity phase which is located on the grain boundaries and space of between the grains.

The lattice parameters $(\mathrm{a}, \mathrm{b}$ and $\mathrm{c})$ were calculated from ten and upper peaks using least square methods. 


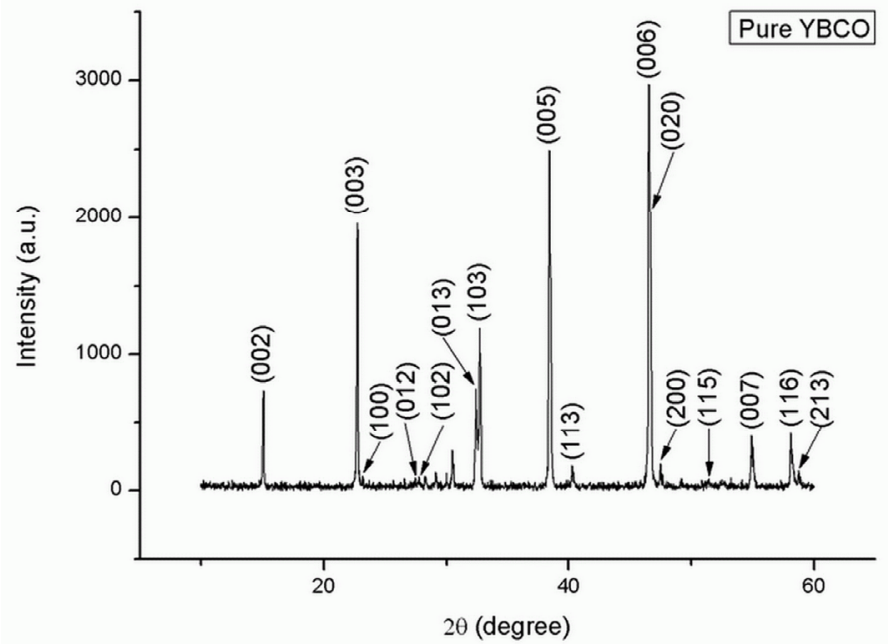

(a)

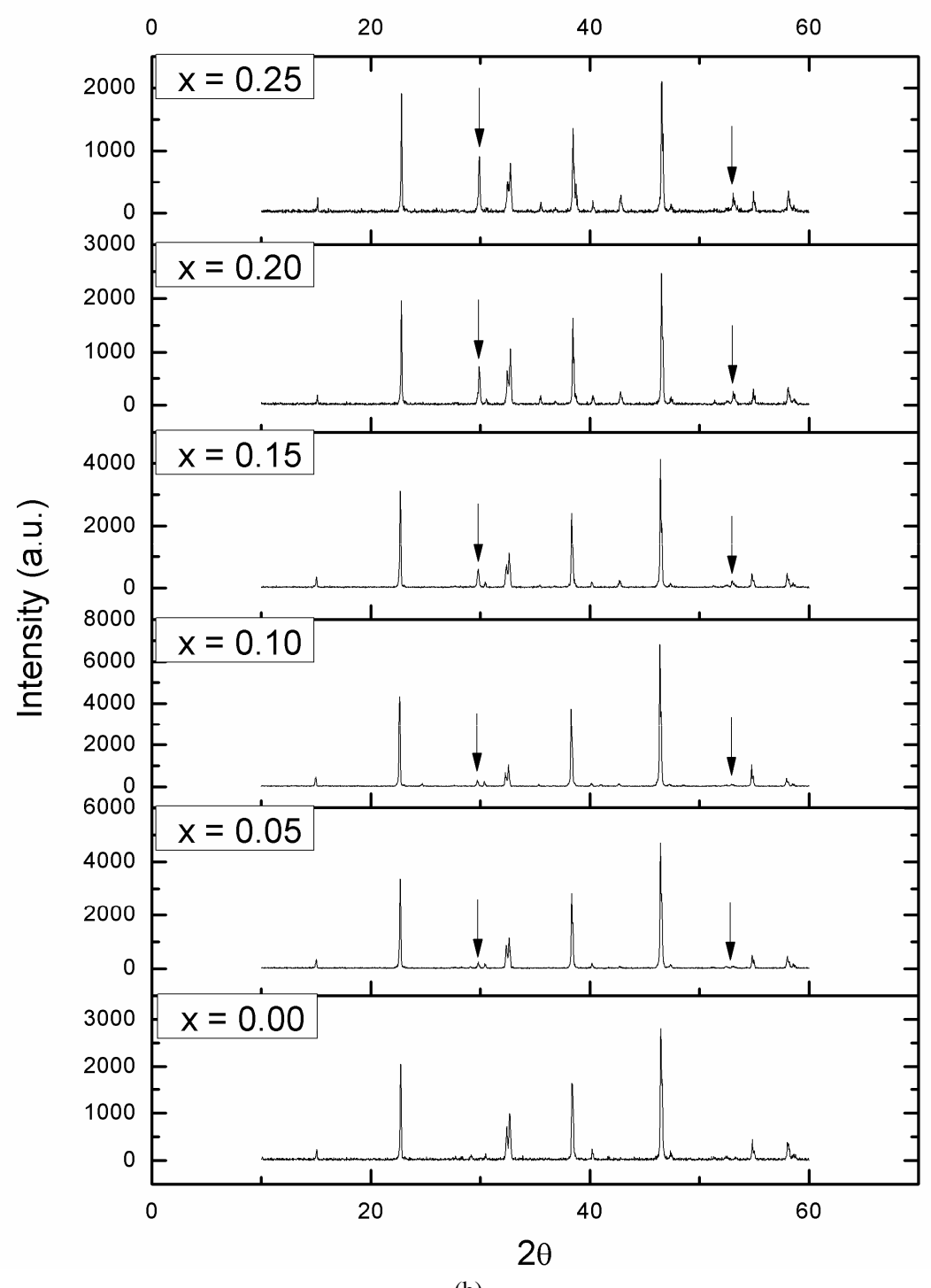

(b)

Figure 1. (a) $\mathrm{XRD}$ patterns for $\mathrm{YBa}_{2} \mathrm{Cu}_{3} \mathrm{O}_{7-\mathrm{y}}$; (b) $\mathrm{XRD}$ patterns for $\mathrm{Y}_{0.6} \mathrm{Gd}_{0.4} \mathrm{Ba}_{2-x} \mathrm{Nb}_{x} \mathrm{Cu}_{3} \mathrm{O}_{7-y}$. 


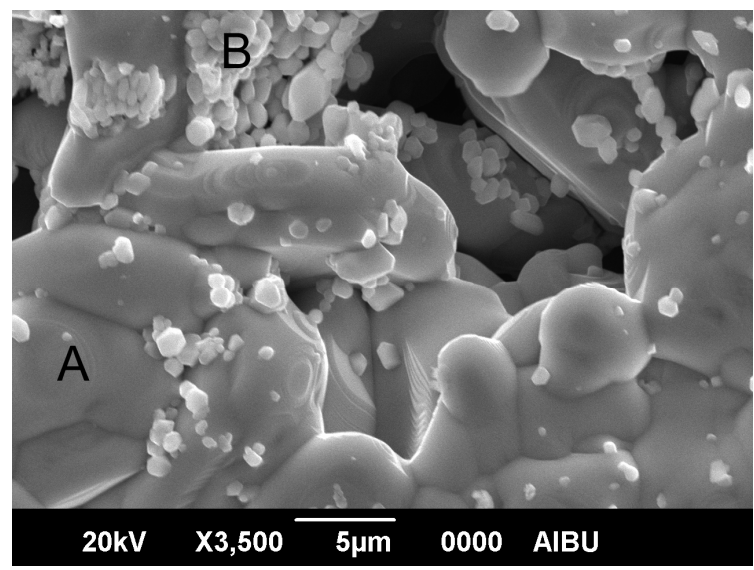

(a)

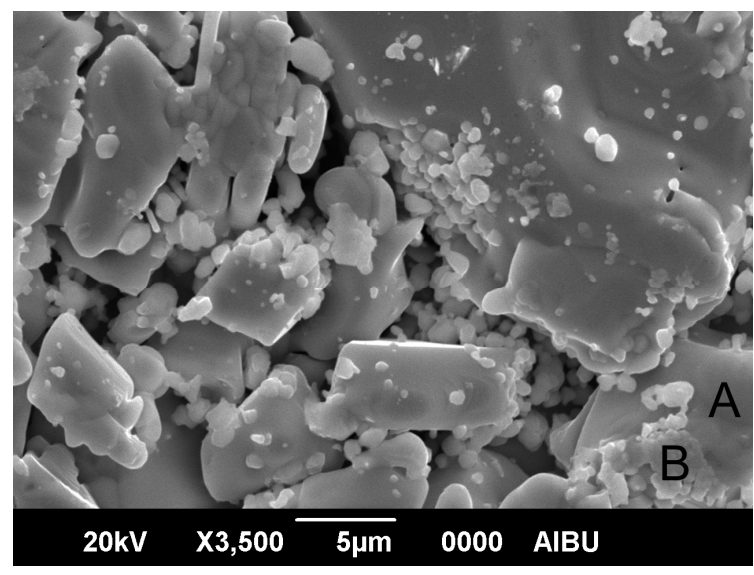

(b)

Figure 2. (a) SEM pictures of the surface structure for samples of YGBNCO with the nominal composition of $x=0.10$; (b) SEM pictures of the surface structure for samples of YGBNCO with the nominal composition of $x=0.20$.

The lattice parameters of $a, b, c, V$ orthorhombicity parameters $\mathrm{a} / \mathrm{b}$ and $\mathrm{c} / \mathrm{b}$ are plotted in Figure 3 versus the $\mathrm{Nb}$ content, $x$, for YGBNCO samples. The lattice constants of the YBCO phase for samples were found to be a $=3.829-3.864 \AA, b=3.887-3.900 \AA, c=11.692-$ $11.736 \AA$ respectively. While $b$ lattice parameter almost remain unchanged. a and $\mathrm{c}$ rapidly increases with the increase of $\mathrm{Nb}$ content with $x \leq 0.10$ and then rapidly decreases with $x \leq 0.10$. We believe that the variations of the lattice parameters are related to the co-doping of $\mathrm{Gd}$ and $\mathrm{Nb}$ in YGBNCO.

The resistivity dependence of temperature in the range of $70-130 \mathrm{~K}$ for all samples, which are respectively normalized to that of the value of the room temperature $(130 \mathrm{~K})$ are shown in Figure 4. Good linear behavior and the metallic behavior for all samples were observed with $\mathrm{T}>94 \mathrm{~K}$. The resistivity at the normal state $(\mathrm{T}>94 \mathrm{~K})$ is measured with $x=0.25$, bigger than with $x=0.05,0.10$,
0.15 and 0.20 . The room temperature resistivity's increases in the doping ranges $0.00 \leq x \leq 0.25$. This result is similar to that of obtained by Strukova et al. [10], and can be explained that the $\mathrm{Nb}$ impurity phase on the grain boundaries promotes an increase in the resistivity value at room temperature.

The dependences of the zero resistance temperature, $\mathrm{T}_{\mathrm{c}}^{\text {offset }}$, and transition temperature, $\mathrm{T}_{\mathrm{c}}^{\text {onset }}$, upon the content of $\mathrm{Nb}$ in $\mathrm{Y}_{0.6} \mathrm{Gd}_{0.4} \mathrm{Ba}_{2-x} \mathrm{Nb}_{x} \mathrm{Cu}_{3} \mathrm{O}_{y}$ are shown in Figure 5, which smoothed with adjacent-averaging method versus $\mathrm{Nb}$ content $x$. It can be found that there is slowly increase of $\mathrm{T}_{\mathrm{c}}^{\text {onset }}$ with the increase of $\mathrm{Nb}$ content (from $92 \mathrm{~K}$ to $95 \mathrm{~K}$ ). This result is good agreement to compare with the other results [16-22], and can be explained as a small amount of $\mathrm{Nb}$ can be caused by the increase of oxygen index because of higher $\mathrm{Nb}$ affinity for oxygen than of $\mathrm{Y}, \mathrm{Ba}$ and $\mathrm{Cu}$.

All the same, it can be found that there is a slowly decrease of zero-resistance temperature, $T_{c}^{\text {offset }}$, with the increase of $\mathrm{Nb}$ content. $\mathrm{T}_{\mathrm{c}}^{\text {offset }}$ almost remain unchanged as $x \leq 0.05(\sim 91.5 \mathrm{~K})$, and then decreases with the increase of $x$ as $x \geq 0.05$. $\mathrm{T}_{\mathrm{c}}^{\text {offset }}$ drops down to $84 \mathrm{~K}$ with $x=0.25$ in Figure 5. The transition width, $\mathrm{T}_{\mathrm{c}}$, which is defined as the temperature difference between $100 \%$ and $0 \%$ in the extrapolated normal-state resistivity value ( $T_{c}^{\text {onset }}$ and $T_{c}^{\text {offset }}$, respectively), increases with the increase of $\mathrm{Nb}$ content. The larger transition width may result from the $\mathrm{YBa}_{2} \mathrm{NbO}_{6}$ phase, impurity, and unidentified phases of the sample due to the $\mathrm{Nb}$ doping. The impurity, $\mathrm{YBa}_{2} \mathrm{NbO}_{6}$ and unidentified phases of the samples were proved by the XRD and SEM experiments which were discussed above. Also, inhomogeneities impurity of the sample may enlarge the width of the superconducting transition, too. The oxygen content and charge transfer were believed to be an important factor for the superconductivity of YBCO.

Critical current density $(\mathrm{Jc})$ values measured in the YBCO and YGBNCO for $x=0.00$ are 89.9 and 85.9 $\mathrm{A} / \mathrm{cm}^{2}$, respectively. Critical current density dependence on the $\mathrm{Nb}$ content is shown in Figure 6. Jc decreases with the increase of $\mathrm{Nb}$ content. We think that this result is related to the $\mathrm{YBa}_{2} \mathrm{NbO}_{6}$ particles which gather between grains.

\section{Conclusions}

In summary, effect of $\mathrm{Nb}$ doped on the superconductivity properties and the structural parameters at $\mathrm{Y}_{0.6} \mathrm{Gd}_{0.4} \mathrm{Ba}_{2-x}$ $\mathrm{Nb}_{x} \mathrm{Cu}_{3} \mathrm{O}_{7-y}$ system with doping range $(0 \leq x \leq 0.25)$ were investigated. The lattice constant of $b$ remains almost unchanged and a and $\mathrm{c}$ increases with the increase of $\mathrm{Nb}$ content with $x \leq 0.10$. However, they decrease with the increase of $\mathrm{Nb}$ content, $x$, with $x \geq 0.10$. The zero resistance transition temperature and Jc decrease with increa- 

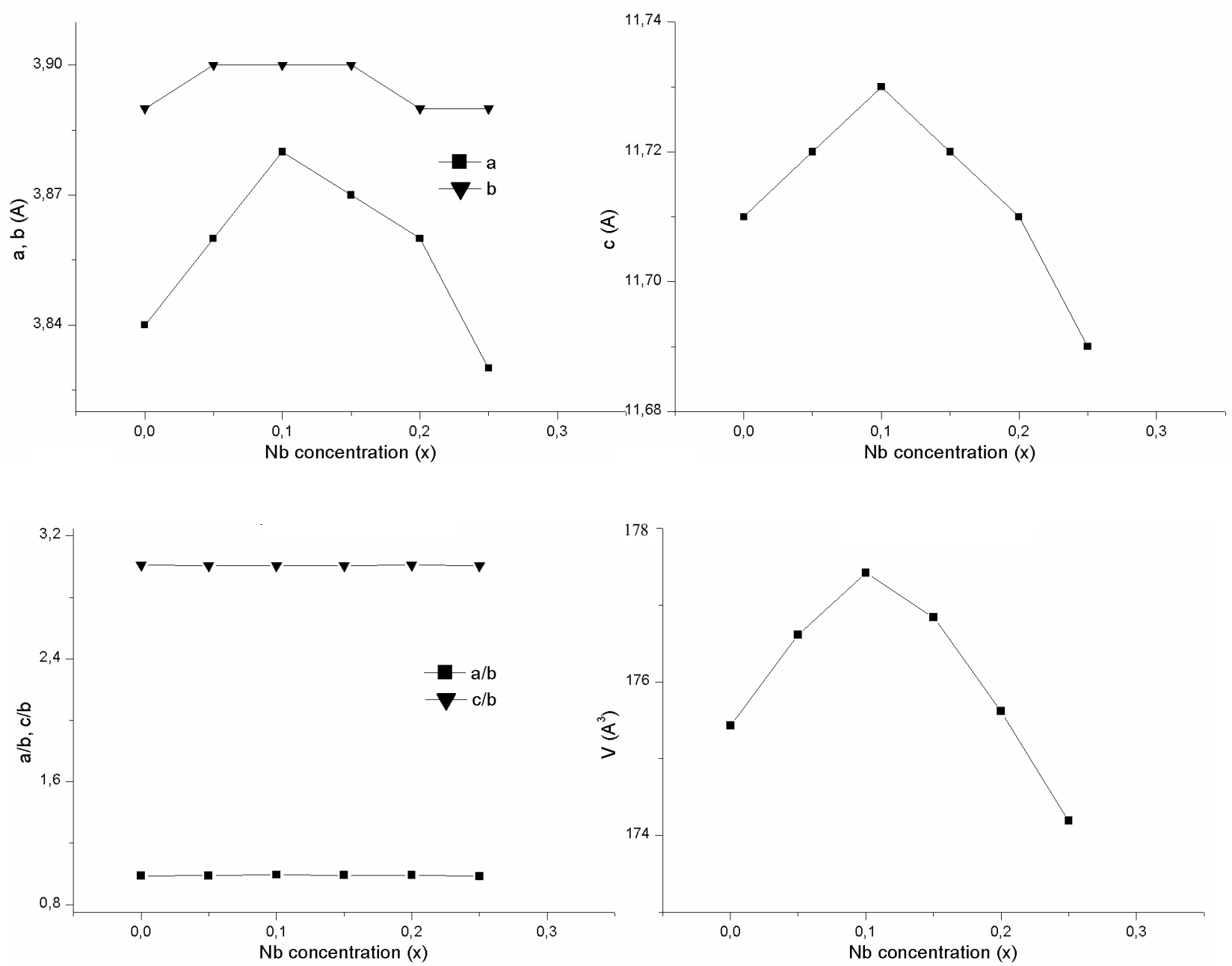

Figure 3. Lattice constants of YGBNCO versus Nb content $(x)$.

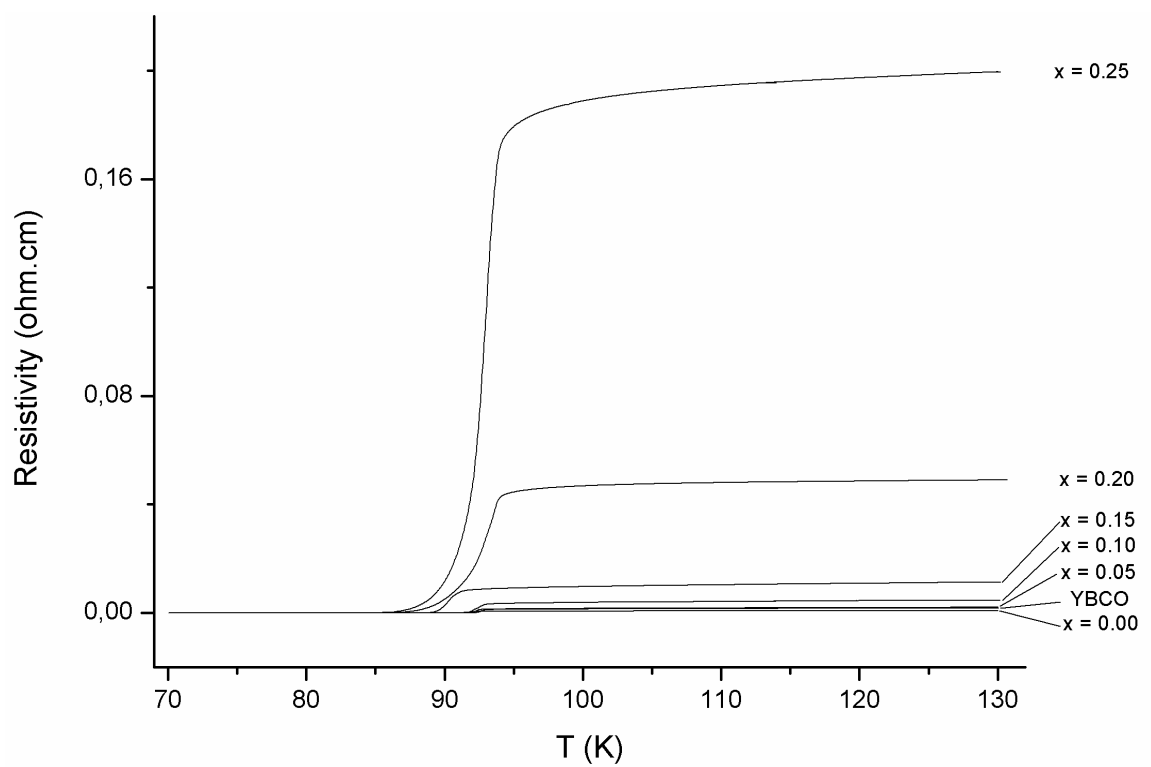

Figure 4. The temperature dependence of the normalized resistivity for YGBNCO. 


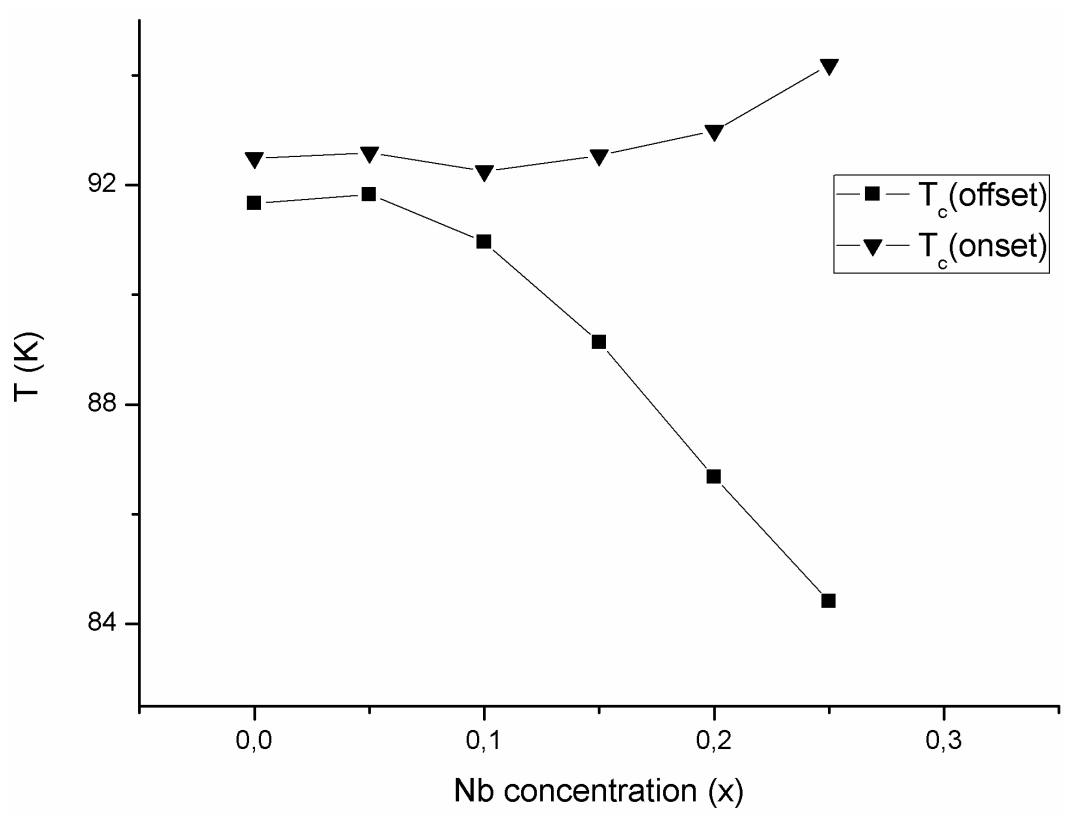

Figure 5. The $T_{c}^{\text {onset }}$ and $T_{c}^{\text {offset }}$ as a function of the Nb content for YGBNCO.

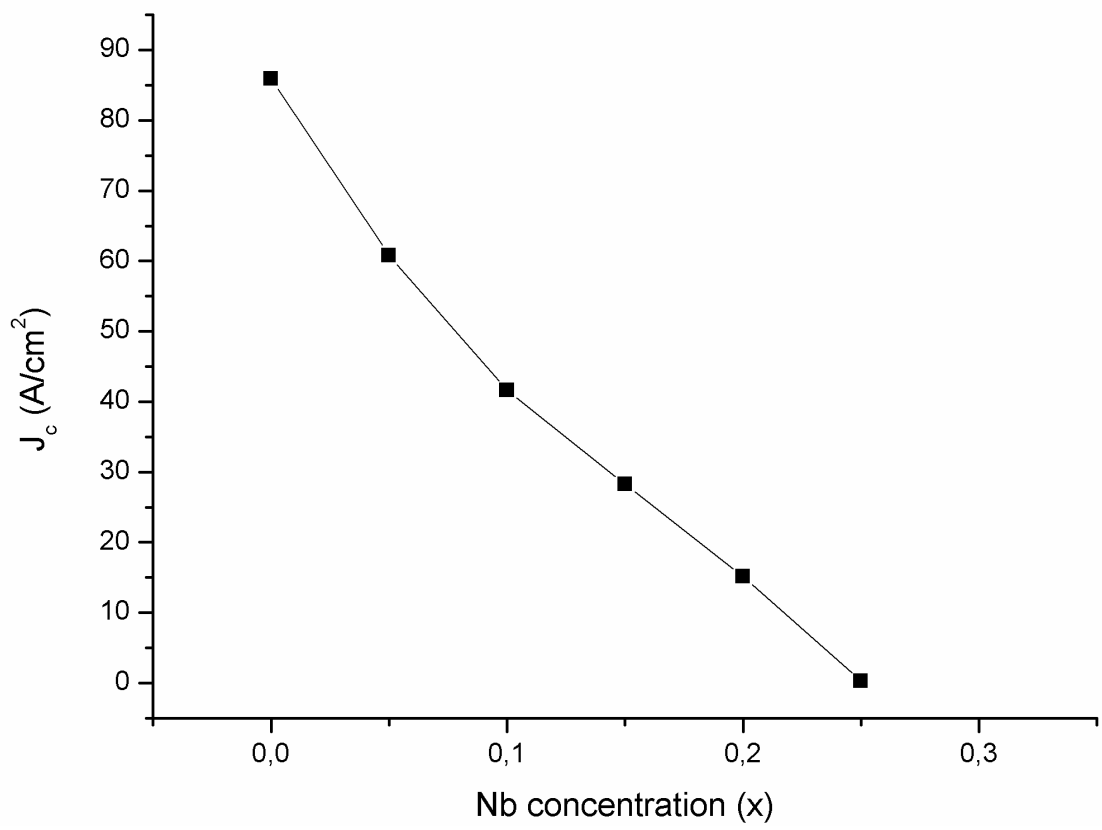

Figure 6. The critical current density $\left(\mathrm{J}_{c}\right)$ as a function of the content of Nb for YGBNCO.

sing $\mathrm{Nb}$ content. But superconductivity did not suppress. These results show that the non-superconducting

$\mathrm{YBa}_{2} \mathrm{NbO}_{6}$ particles gathered on sample surface and between grains.

\section{Acknowledgements}

This research was supported by the Council of the Scientific Research Projects at Selçuk University. Grant No. 0710103.

\section{REFERENCES}

[1] M. K. Wu, J. R. Ashburn, C. J. Torng, P. H. Hor, R. L. Meng, L. Gao, Z. J. Huang, Y. Q. Wang and C. W. Chu, "Superconductivity at $93 \mathrm{~K}$ in a New Mixed-Phase Yb-Ba-Cu-O Compound System at Ambient Pressure," Physics Review Letters, Vol. 58, No. 9, 1987, pp. 908910. doi:10.1103/PhysRevLett.58.908

[2] M. Murakami, "Processing of Bulk YbaCuO," Super- 
conductor Science Technology, Vol. 5, No. 4, 1992, pp. 185-203. doi:10.1088/0953-2048/5/4/001

[3] T. D. Dzhafarov, "Diffusion in High-Temperature Superconductors," Physics State Solid A, Vol. 158, No. 2, 1996, pp. 335-358. doi:10.1002/pssa.2211580202

[4] B. Batlogg, "Cuprate Superconductors: Science beyond High Tc," Solid State Commune, Vol. 107, No. 11, 1998, pp. 639-647. doi:10.1016/S0038-1098(98)00296-8

[5] J. M. S. Skakle, "Crystal Chemical Substitutions and Doping of $\mathrm{YBa}_{2} \mathrm{Cu}_{3} \mathrm{O}_{\mathrm{x}}$ and Related Superconductors," Material Science Engineering, Vol. R23, 1998, pp. 1-40.

[6] P. Mele, K. Matsumoto, T. Horide, A. Ichinose, M. Mukaida, Y. Yoshida, S. Horii and R. Kita, "Incorporation of Double Artificial Pinning Centers in $\mathrm{YBa}_{2} \mathrm{Cu}_{3} \mathrm{O}_{7}$-D Films," Superconductor Science Technology, Vol. 21, No. 1, 2008, p. 015019.

doi:10.1088/0953-2048/21/01/015019

[7] M. H. Abdullah and B. T. Tan, "Superconducting Properties of Niobium-Doped Y-Ba-Cu-Nb-O Superconductors," Solid State Commune, Vol. 93, No. 1, 1994, pp. 9396.

[8] I. Grekhov, L. Delimova, I. Liniychuk, O. Semchinova and M. Baydakova, "Superconductor-Insulator Transition in $\mathrm{YBa}_{2} \mathrm{Cu}_{3-x} \mathrm{Nb}_{x} \mathrm{O}_{7}$ Material," Physics C, Vol. 235-240, 1994, 1295-1296.

[9] K. V. Paulose, J. Koshy and A. D. Damodaran, "Observation of Superconductivity in $\mathrm{Nb}_{2} \mathrm{O}_{5}$ Doped $\mathrm{YBa}_{2} \mathrm{Cu}_{3} \mathrm{O}_{7-\delta}$ Compound by Rapid Quenching," Japanese Journal of Applied Physics, Vol. 30, 3B, 1991, pp. L458-L460.

[10] G. K. Strukova, I. S. Smirnova, S. A. Shevchenko, A. I. K olyubakin, I. I. Zver'kova, V. Sedykh, A. A. Polyanskii, L. A. Dorosinskii and V. S. Shekhtman, "Effect of Nb Doping on Properties of Y-Ba-Cu Ceramics," Superdome Science Technology, Vol. 6, No. 8, 1993, pp. 589-592. doi:10.1088/0953-2048/6/8/006

[11] M. Bennahmias, H. B. Radousky, T. J. Goodwin and R. N. Shelton, "Superconductivity and Magnetism in Niobium Doped $\mathrm{YBa}_{2} \mathrm{Cu}_{3} \mathrm{O}_{7}$ Related High Tc Ceramics," Journal of Electronic Materials, Vol. 22, No. 10, 1993, p. 1189.

[12] Y. Hikichi, T. Maruta, S. Suzuki, M. Miyamoto, S. Okada and K. Kudou, "Property and Structure of $\mathrm{YBa}_{2} \mathrm{Cu}_{3} \mathrm{O}_{7-x^{-}}$ $\mathrm{Nb}_{2} \mathrm{O}_{5}$ Composite," Japanese Journal of Applied Physics, Vol. 31, No. 9A, 1992, pp. L1232-L1235.

[13] M. Kuwabara and N. Kusaka, "Microstructure and Su- perconducting Properties in $\mathrm{YBa}_{2} \mathrm{Cu}_{3} \mathrm{O}_{7-x}$ Ceramics Doped with $\mathrm{Nb}_{2} \mathrm{O}_{5}$ and $\mathrm{WO}_{3}$," Japanese Journal of Applied Physics, Vol. 27, No. 8, 1988, pp. L1504-L1506.

[14] N. G. Suresha, S. Higo, Y. Hakuraku, T. Otawa, Y. Honjo and T. Ogushi, "High Temperature Superconductivity in Y-Ba-Cu-Nb-O System," International Journal Modern Physics B, Vol. 2, No. 3-4, 1988, pp. 435-441. doi:10.1142/S0217979288000299

[15] K. Eguchi, K. Kuma and H. Arai, "An Effect of Substitution on the Superconductive Property in Perovskite-Like Oxides," Molecular Crystals and Liquid Crystals, Vol. 184, No. 1, 1990, pp. 153-157. doi:10.1080/00268949008031754

[16] S. Higo, Y. Hakuzaku, T. Ogushi, I. Kawano and Y. Ishikawa, "Effects of a Partial Substitution of $\mathrm{Cu}$ Elements by $\mathrm{Nb}$ Eelements in YBaCuO System," Molecular Physics Letters B, Vol. 4, No. 12, 1990, pp. 823-830. doi:10.1142/S021798499000101X

[17] G. M. Kammlott, T. H. Tiefel and S. Jin, "Recovery of 90 K Superconductivity in Transition-Metal-Doped-Y-BaCu-O," Applied Physics Letters, Vol. 56, No. 24, 1990, p. 2459. doi:10.1063/1.103255

[18] A. E. Ali, K. A. Azezb, I. A. Al-Omaric, J. Shobakia, M. K. Hasan (Qaseer), B. A. Albissb, K. Khasawnieha, A. K. Ziqd and A. F. Salem, "The Paramagnetic Contribution in Magnetization Behavior of $\mathrm{Y}_{1-x} \mathrm{Gd}_{x} \mathrm{Ba}_{2} \mathrm{Cu}_{3} \mathrm{O}_{7}$," Physical $B$, Vol. 321, 2002, pp. 320-323.

[19] C. Taka, S. Teshima and A. Nishida, "Effects of Y Substitution oan Oxygen Deficiency on the Superconducting Transitions in $\mathrm{Y}_{x} \mathrm{Gd}_{1-x} \mathrm{Ba}_{2} \mathrm{Cu}_{3} \mathrm{O}_{7}$, " Physical C, Vol. 378381, 2002, pp. 344-348.

[20] J. Yulei, X. Ling, R. Hongtao and Z. Minghui, "Fabrication and Properties of (Y,Gd)BCO Superconductors," Journal of Rare Earths, Vol. 22, No. 6, 2004, pp. 867-870.

[21] K. Öztürk, Ş. Çelik, U. Çevik and E. Yanmaz, "The Effect of Gd diffusion-Doped on Structural and Superconducting Properties of $\mathrm{YBa}_{2} \mathrm{Cu}_{3} \mathrm{O}_{7-x}$ Superconductors," Journal of Alloys and Compounds, Vol. 433, 2007, pp. 46-52.

[22] C. G. S. Pillai and A. M. George, "Substitution of Copper by Niobium in Superconducting $\mathrm{YBa}_{2} \mathrm{Cu}_{3} \mathrm{O}_{7-\delta}$, "Journal of Material Science Letters, Vol. 11, No. 23, 1992, pp. 1639-1640. doi:10.1007/BF00740858 